Behavior and Social Issues, 13, 134-135 (2004). (C) H. S. Pennypacker. Readers of this article may copy it without the copyright owner's permission, if the author and publisher are acknowledged in the copy and the copy is used for educational, not-for-profit purposes.

\title{
Complexity ANd Selection: A TeMPlate For NATion BUILDing?
}

\author{
H.S. Pennypacker \\ University of Florida and Mammatech Corporation
}

When I completed my first reading of the manuscript by Glenn and Malott (2004), I was left with the feeling one has after receiving a good massage - soothed, relaxed and content. There was no heavy lifting required to appreciate their clear, direct application of the basic concepts of variation and selection to the dynamics of organizational change. The extension of the selection metaphor from ontogenetic development of the repertoire of an individual to the complex activities of organizations is compelling. It provides a behavior analyst like me, who is also involved in a commercial venture, with a comfortable heuristic device with which to contemplate the constantly changing character of our organization and its adaptation to the commercial environment.

Glenn and Malott nicely catalogue the internal dynamics of organizational components that induce variability leading to selection and change. While I still chafe a bit at the assertion that organizations behave (Johnston \& Pennypacker, 1980, p 48), little harm is done because the emphasis here is on selection, not on the dimensional details of the behavior per se. Their concept of a receiving system as sufficient to maintain output of an organizational element was, for me, a valuable addition to my arsenal as a manager. At times, I have had difficulty identifying within my own organization the contingencies of reinforcement responsible for maintenance of behavior for which I can find no functional justification. Now, at least, I have another category in which to search.

While pondering what I could contribute in these pages by way of reaction to this nicely written, but hardly controversial, manuscript, I put it aside and picked up that day s copy of the Wall Street Journal. The headline on the left column above the fold of the front page read Globalization Gets Mixed Report Card in U.S. Universities." The article, written by Jon E. Hilsenrath, explored in detail a dispute between Joseph Stiglitz, last year s Nobel Prize winner in economics, and Jagdish Bhagwati, his colleague at Columbia University. Briefly, Stiglitz argues that 1990s-style globalization-broadly defined as the freer movement of money, goods, services and people across borders - has put many developing countries through a decade of financial and economic turmoil (Hilsenrath, 2002). Bhagwati is an advocate of free trade and accuses Stiglitz of trying to revive dinosaurs which we hoped we had slain." In the audience for this discussion was Santiago Pardo, a graduate student at Columbia (the university) who was formerly trade minister of Colombia (the country). He, like a large number of other foreign nationals now in graduate departments of economics at American universities, will soon occupy an important position in a developing country. What such students are learning will have a major impact on the economic and social futures of their countries.

In her book World on Fire," Amy Chua of Yale Law School aligns herself with the Stiglitz position. She argues that premature imposition of democracy and free market 


\section{COMMENTARIES ON COMPLEXITY AND SELECTION}

economics on unprepared citizens of developing countries leads inevitably to the formation of a market-dominant minority. This minority quickly acquires the tools of production and distribution and becomes prosperous. Eventually they are politically attacked by the newly enfranchised but still impoverished majority. Often, these attacks are violent, as illustrated by the anti-Chinese burning, looting and killing by Muslims in Indonesia. Chua goes on to account for much of the hatred that energized the events of September 11, 2001 in these terms, comparing the United States to a market-dominant minority with respect to the rest of the entire world, particularly the Arab segment.

Of what possible relevance to the Glenn and Malott article is this discussion of globalism, politics, and economics? Put simply, how would the future be different if those students at Columbia were also reading Glenn and Malott? What would change if diplomats, policy makers and economists began to view their missions as involving responsibility for guiding the evolution of emerging cultures in accordance with the principles of variation and selection? Let us consider some of the possibilities.

\section{A Proposal}

Sidman (2001) has pointed out that if we are to reverse the pattern of envy and hatred that gives rise to terrorism, we must find a way to make positive reinforcement (including money in the form of foreign aid) contingent on approximations of prosocial behavior on the part of governments and their citizens. A good beginning, therefore, would be to recognize that wholesale infusions of money into marginal economies usually fails to accomplish anything but fattening the coffers of the ruling class. Equally futile is the practice of distributing money non-contingently or worse, for the purpose of protection from mob violence. This has happened all too frequently in African countries; e.g., Zimbabwe (Chua, 2003, p. 129).

Following the analysis of Glenn and Malott, an administrative structure attached to the granting agency (IMF, World Bank, UNESCO, USAID, etc.) should be established to manage the distribution of aid funds. The charge to this structure would be to work within the indigenous governing structure to insure that funds are being used to promote variation and selection of practices that benefit the populace. The structure would have no opportunity for differential benefit so corruption would be discouraged. The structure would have the power, subject to review from a higher echelon, to suspend or withdraw continued funding.

The administrative structure just defined would function as the external environment in the Glenn and Malott analysis. As such, it would exercise loose but ultimately effective constraints over the types of external environmental events that could impinge on the emerging economic system. It is important that care be taken not to suppress variability in the activities of the elements of the organization. Too often, heavy-handed bureaucratic dictates on the part of organizations like to the World Bank or International Monetary Fund (IMF) serve to defeat the intent of the original program (Chua, 2003, pp150-151). Like the organization of Glenn and Malott, this cultural experiment would have an accounting system. Whereas in a conventional organization success is measured 
by the bottom line and transfer of value to the shareholders, in this case we would monitor the economic health of the population, measured in terms of per capita annual income or standard of living.

With the administrative environment in place, we can begin to examine the relevance of some of Glenn and Malott s other dimensions. Glenn and Malott properly abhor complexity. At the level of a functioning culture, complexity is a given, but their caveats should be heeded. There will be tendency in this organization, like all others, for subunits to form that have as their primary function the perpetuation of their own existence (Glenn \& Malott, 2004; Pennypacker, 1992). History assures us that allowing this to happen is to create future problems. Entities such as this that successfully compete for resources thereby deplete the overall output of the organization, resulting in concomitant reduction in the economic indicator.

Because there may be many more people in the organization than can be efficiently deployed, at least in the early stages, it may be necessary to subsidize smaller contributions by a larger number of people. Allowing the free market principle to operate on the labor supply will all but guarantee the type of backlash Chua describes. Thus, variability with respect to numbers of people employed is to be encouraged with full employment as the goal. Of course, variations in methods of production that increase per capita productivity should also be selected, but not at the expense of increased unemployment.

Efforts should be made at all stages to guide the evolution of the cultural structures to a stage of self-sufficiency. In this respect, most observers agree that globalization has been a good thing. The rapid industrialization and market development of China, for example, has greatly lessened international tensions with that country. The expansion of light manufacturing and exporting in that economy has had a salutary impact on the lives of the people which should serve as a model for other developing economies. Note that the political system has not undergone such extensive change. The reinforcement contingencies maintaining those activities are less subject to evolution since they tend to be involved primarily with self-service. As long as political practices do not interfere with economic progress, they exert an essentially benign influence on the evolutionary process, much like that of the human appendix.

By now, the essence of my argument should have become clear. Thoughtful students of the science of behavior have followed Skinner in calling for application of the discoveries and principles of the science to the solution of human problems at every level of complexity. These calls have been eloquent, perhaps none more so than Sidman s (2001) discussion of geopolitical matters in Coercion and Its Fallout. Lacking, however, has been a coherent model to assist in the organization of the various suggestions Sidman and others have made. Glenn and Malott have provided such a model and we can now get on with the business of contributing our special expertise to the collective effort to improve life on this planet.

What can thoughtful behavior analysts do to assist in this undertaking? Several suggestions follow. First, we should acquaint our colleagues in related disciplines such as political science and economics with the ideas promulgated by Glenn and Malott. In 


\section{COMMENTARIES ON COMPLEXITY AND SELECTION}

doing this, we should stress the origins of their ideas in evolutionary biology, even as we point out that behavior is a modulus of biological adaptation and is a lawful subject matter. We should invite those colleagues to join us in analyzing current world events in these terms rather than the usual vernacular of the media. We could even suggest that such analyses lead to recommendations for action, including contacting political figures.

Besides sharing our perspective with colleagues, we should be willing to share them with the public. Submitting op ed pieces to the local paper is a good way to get new ideas into circulation. These have the advantage of becoming archival, unlike email discussions on the internet. Of course, we should be willing to develop these ideas for the benefit of local political leaders who, while not directly involved with international relations, can see the applicability of this approach to managing local civic problems.

In all efforts to communicate these ideas to a larger audience, we should be careful to avoid infusing political systems into the discourse. We are discussing the application of established principles of behavioral selection to the solution of cultural problems. As such, we are emphasizing function over structure. This will seem awkward to many outside our discipline who believe, along with Thomas Friedman (as cited in Chua, 2003) that market development and democracy are fully compatible. There have been many attempts to impose democratic processes on what previously were totalitarian states. Unless these changes are accompanied by changes in the reinforcement histories of the individuals comprising the regime (not a likely scenario), the old practices soon reemerge. The result, as Chua makes clear, is that premature imposition of political change leads to disruption, often taking the form of rebellion.

Separating political philosophy from cultural design is a difficult assignment. We are aided substantially by Glenn and Malott's effort to bring the organizing principles of biological and behavioral evolution to the task. To the extent that we are able to apply the latter in an empirical, self-correcting manner using carefully gathered evidence to justify modifications to practice, we will be well on the way to achieving a political philosophy based on the science of behavior. Such an accomplishment may be necessary if we are to sustain our very existence.

\section{REFERENCES}

Chua, A. (2003). The world on fire. New York: Doubleday.

Friedman, T.L. (2000). The Lexus and the olive tree. New York: Anchor Books.

Glenn, S.S. \& Malott, M.E. (2004). Complexity and election: Implications for organizational change. Behavior and Social Issues, 13, 89-106. http://dx.doi.org/10.5210/bsi.v13i2.378

Hilsenrath, J.E. (2002, December 2). Globalization gets mixed report card in U.S. universities. The Wall Street Journal, pp.A1, A14.

Johnston, J.M. \& Pennypacker, H.S. (1980). Strategies and tactics of human behavioral research. Hillsdale, NJ.: Lawrence Erlbaum Associates.

Pennypacker, H.S. (1992). Is behavior analysis undergoing selection by consequences? American Psychologist, 47, 1491-1498. http://dx.doi.org/10.1037/0003-066X.47.11.1491

Sidman, M. (2001). Coercion and its fallout. Boston: Authors Cooperative. 